\title{
Genetic epidemiology of Type 2 diabetes mellitus and complications in the Brazilian population
}

\author{
J.S. Campos ${ }^{1 *}$, K.F. Santos ${ }^{1 *}$, C.C.P. Costa $^{1}$, J.B.S. Barros ${ }^{1}$, \\ V.S.S. Gonçalves ${ }^{3}$, L.P. Assunção ${ }^{1}$, A.A.S. Reis ${ }^{1,2}$ and R.S. Santos ${ }^{1,2}$ \\ ${ }^{1}$ Laboratório de Patologia Molecular, Instituto de Ciências Biológicas, \\ Universidade Federal de Goiás, Goiânia, GO, Brasil. \\ ${ }^{2}$ Departamento de Bioquímica e Biologia Molecular, Instituto de Ciências \\ Biológicas (ICBII), Universidade Federal de Goiás, Goiânia, GO, Brasil. \\ ${ }^{3}$ Programa de Pós-Graduação em Saúde Coletiva, Faculdade de Ciências da \\ Saúde, Universidade de Brasília, Brasília, DF, Brasil. \\ *These authors contributed equally to this study \\ Corresponding author: R.S. Santos / A.A.S. Reis \\ E-mail: rdssantos@ufg.br / angela@ufg.br
}

Genet. Mol. Res. 21 (1): gmr18969

Received September 08, 2021

Accepted December 21, 2021

Published January 31, 2022

DOI http://dx.doi.org/10.4238/gmr18969

\begin{abstract}
Type 2 diabetes mellitus (T2DM) is a chronic, complex, multifactorial and polygenic disease, constituting one of the greatest public health challenges worldwide. The genetic background has been shown to strongly influence the disease's susceptibility. We performed genetic screening of risk-variants for T2DM and complications in the Brazilian population. This systematic review is registered in the PROSPERO platform under number CRD42020153032. The searches were conducted in Virtual health library (BVS), EMBASE, Pubmed/NCBI, Scopus, and Web of Science databases, including only case-control studies that related genetic polymorphisms with the risk of developing the disease in the Brazilian population. Among the search results, we also extracted data regarding the susceptibility of developing macro/microvascular complications. Sixteen case-control studies were included, of which 10 addressed T2DM susceptibility and six the disease complications. A total of 4122 individuals were
\end{abstract}


included in the analyses of susceptibility to T2DM, and 1443 in those of susceptibility to complications of the disease. Our findings demonstrate the participation of four main mechanisms in T2DM pathophysiology: glycolytic dysregulation, lipid metabolism, insulin resistance, and inflammatory processes. Among the eight polymorphisms linked to disease susceptibility, we highlight rs7903146 (C/T) in the TCF7L2 gene and rs1800471 $(25 \mathrm{C} / \mathrm{G})$ in the $T G F-\beta 1$ gene for diabetic retinopathy. In haplotype analysis, two sets were associated with T2DM susceptibility ( $A D I P O Q$ and DIO2 genes), and two sets in the UCP2 gene were associated with diabetic retinopathy and nephropathy. Data from this study characterize the genetic profile of the Brazilian population for susceptibility to T2DM and its complications. This is the first genetic epidemiology study to screen risk variants associated with this disease in Brazil. With this mapping, we aimed to contribute to the development of molecular diagnostic technologies and precision medicine, such as a genetic panel for T2DM susceptibility in the Brazilian population.

Key words: Type 2 Diabetes Mellitus; Genetic epidemiology; Genetic polymorphisms; Genetic susceptibility; Brazilian population

\section{INTRODUCTION}

Type 2 Diabetes Mellitus (T2DM) is a chronic disease characterized by hyperglycemia due to secretory dysfunction of pancreatic cells and/or insulin resistance (DeFronzo et al., 2015). The disease is one of the main public health problems in the world, responsible for high rates of morbidity and mortality in the population (GarcíaChapa et al., 2017). Among the diabetes mellitus (DM) classifications, T2DM is the most common, accounting for $90-95 \%$ of cases (DeFronzo et al., 2015); it typically affects individuals after the fourth decade of life (Wilmot and Idris, 2014). However, the disease can also affect children and adolescents (Wilmot and Idris, 2014).

Brazil is the fifth country with the highest number of patients with diabetes worldwide, with around 16.8 million people suffering from the disease (International Diabetes Federation, 2019). According to estimates, approximately 26 million Brazilians will have the disease in 2045. Furthermore, epidemiological data also indicate that Brazil has the highest mortality rate in patients with diabetes, mainly associated with delayed diagnosis, which usually occurs with complications' onset (International Diabetes Federation, 2019).

Patients with T2DM are frequently asymptomatic or oligosymptomatic over a very long period, making early diagnosis a challenge (DeFronzo et al., 2015; Correr et al., 2020). A multicenter study performed in Brazil showed that almost half of the patients with diabetes in the study (46\%) were not diagnosed with the disease (Malerbi and Franco, 1992), corroborating world estimates, where one in two adults with diabetes has not been diagnosed with the disease (International Diabetes Federation, 
2019). Early diagnosis can help prevent the development of macrovascular and microvascular complications (retinopathy, neuropathy, and nephropathy) (Correr et al., 2020).

In Brazil, the disease also has a relevant impact on public health (Correr et al., 2020), with substantial costs for the Brazilian Unified National Health System (SUS) (Rosa et al., 2014). Between 2010 and 2016, SUS spending attributable only to diabetes with chronic kidney diseases almost doubled, from US\$ 1.4 million to US\$ 2.6 million (Nilson et al., 2020). Most of the increased cost is associated with T2DM and results from the presence of complications and their complexities (Rosa et al., 2014; Correr et al., 2020). However, despite the impact on public health, delayed diagnosis, and social consequences, there are still no specific biological predictors for identifying the disease.

The etiology of T2DM is complex and involves interactions between environmental and genetic factors (DeFronzo et al., 2015). Moreover, the disease shows a strong genetic basis with polygenic character (Lyssenko and Laakso, 2013; DeFronzo et al., 2015). Several genetic alterations have been associated with susceptibility to the disease. However, the mechanisms underlying the genetic and molecular bases remain unclear (Janipalli et al., 2012; Lyssenko and Laakso, 2013). Genetic studies in T2DM patients have shown that differences in the genetic background of populations and the lifestyle between ethnic groups can play a role in the disease's development (DeFronzo et al., 2015; García-Chapa et al., 2017). Regarding this, genetic polymorphisms can be strong factors for disease' susceptibility, where the association with the pathology may vary among ethnic groups (Golden et al., 2019).

Understanding the genetic factors related to T2DM in the Brazilian population can contribute to the elucidation of pathogenic and molecular mechanisms involved in disease susceptibility and may contribute to the early diagnosis and development of therapeutic strategies. There are few studies on the genetic epidemiology of the disease in the Brazilian population. Thus, in this systematic review, we examined the genetic polymorphisms associated with the susceptibility of T2DM in the Brazilian population, as well as the genetic polymorphisms associated with its complications in the population with diabetes.

\section{MATERIAL AND METHODS}

\section{Registration}

This systematic review was registered in the International Prospective Register of Systematic Reviews (PROSPERO) under the number CRD42020153032 on January 24th, 2020. Our results are reported according to the Preferred Reporting Item for Systematic Review and Meta-Analysis (PRISMA) (Moher et al., 2009).

\section{Information sources and search strategies}

To formulate the search strategy, we adopt the PEOS acronym, designed for systematic reviews and meta-analysis of etiology and risk factors (Moola et al., 2020): 
$\mathrm{P}$ (population): Brazilian adults with T2DM living in Brazil; E (exposure): genetic polymorphisms; O (outcome): susceptibility in the development of T2DM and/or in the development of its complications; and S (study design): case-control studies. The complications associated with T2DM were used as a secondary outcome.

The searches were performed on November $5^{\text {th }}, 2020$ in Virtual Health Library (BVS), EMBASE, SCOPUS, Pubmed/NCBI, and Web of Science databases. Two independent reviewers evaluated the search strategy following the Peer Review of Electronic Search Strategies (PRESS) (McGowan et al., 2016) adapting it to each database (Table S1).

\section{Eligibility criteria}

The inclusion criteria were: inclusion of only case-control studies that addressed genetic polymorphisms statistically associated $(\mathrm{p}<0.05)$ with susceptibility to T2DM and/or its complications in the Brazilian population. For complications, only macrovascular and microvascular complications were considered. We excluded studies in non-humans, with no significant association with the disease and/or complications or studies performed in other populations, reviews, letters, personal opinions, and book chapters. No restrictions on language, publication date, or status were applied.

\section{Study selection}

All studies obtained from the searches were imported to the Rayyan platform (Ouzzani et al., 2016) to optimize the selection process. The initial screening was carried out by reading the title and abstracts (Phase I). The studies selected in phase I were read in full (Phase II) and those that met the eligibility criteria were included in this review. Two independent reviewers performed all stages of the study selection. A third reviewer solved disagreements.

\section{Risk of methodological bias in individual studies}

The risk of methodological bias was assessed using a critical tool for casecontrol studies, formulated by the Joanna Briggs Institute (Institute TJB). This tool has ten questions that must be answered with "Yes", "No", "Unclear" or "Not applicable". A study that answered "Yes" to all questions is classified as low risk of bias (Institute TJB).

Two independent reviewers assessed methodological bias. A third reviewer performed data synthesis and discrepancies were resolved by consensus between the reviewers. The result of the evaluation of bias in the studies was expressed as a graph. Furthermore, the assessment of bias was not used as an exclusion criterion for studies.

\section{Data extraction and synthesis}

We conducted a qualitative analysis based on the following data extracted from selected articles: (a) first author and year of publication (reference); (b) region of Brazil 
(state); (c) ethnicity; (d) mean age of case and control groups; (e) number of individuals according to sex for case and control groups; (f) gene; (g) gene location; (h) genotyping methods; (i) investigated polymorphism; (j) type of polymorphism; (k) sample size of case and control groups; (1) genotypic or allelic comparison performed and their frequencies for the case and control groups; (m) odds ratio and 95\% confidence interval; (n) p-value; (o) T2DM complications; (p) Hardy-Weinberg equilibrium; and (q) haplotypes and their respective susceptibilities.

The data extraction was performed by two independent reviewers and checked by a third one. The official nomenclature of genes, genomic location, and polymorphisms were verified in the National Center for Biotechnology Information (NCBI) database at Gene (https://www.ncbi.nlm.nih.gov/gene) and dbSNP (https://www.ncbi.nlm.nih.gov/snp/) sections.

\section{Statistical analysis}

Performing a meta-analysis with the data obtained in this study was unviable due to the heterogeneity of the data and methods applied in the original studies. To obtain odds estimates for all polymorphisms, in studies where the OR, 95\% CI, and pvalue were not described, these values were calculated using logistic regression. We performed genotypic comparisons using the models: wild vs mutant; wild vs heterozygous; and wild $v s$ heterozygous + mutant, to assess possible significant correlations. Only results with significant p-values, which conferred odds to T2DM were included. The statistical analyses were performed using the RStudio ${ }^{\circledR}$ software (version 3.5.3) and considered significant when $\mathrm{P}<0.05$.

\section{RESULTS}

\section{Study selection}

Through the search, 2,414 articles were initially obtained. After excluding 880 duplicate data, 1,534 studies were initially screened in phase I, and 44 were selected for phase II. Another 10 studies were identified in additional sources; therefore, 54 articles were analyzed in phase II, and 16 case-control studies were included in this review, where 10 addressed T2DM susceptibility and six addressed macrovascular or microvascular complications in patients with diabetes. A total of 4122 individuals were included in the analyses of susceptibility to T2DM, and 1443 in those of susceptibility to complications of the disease.

The references of retrieved articles were manually checked to obtain more data. Furthermore, unavailable studies or with insufficient data had their authors contacted at least twice. However, no contact was returned. Figure 1 details the information on study identification. 


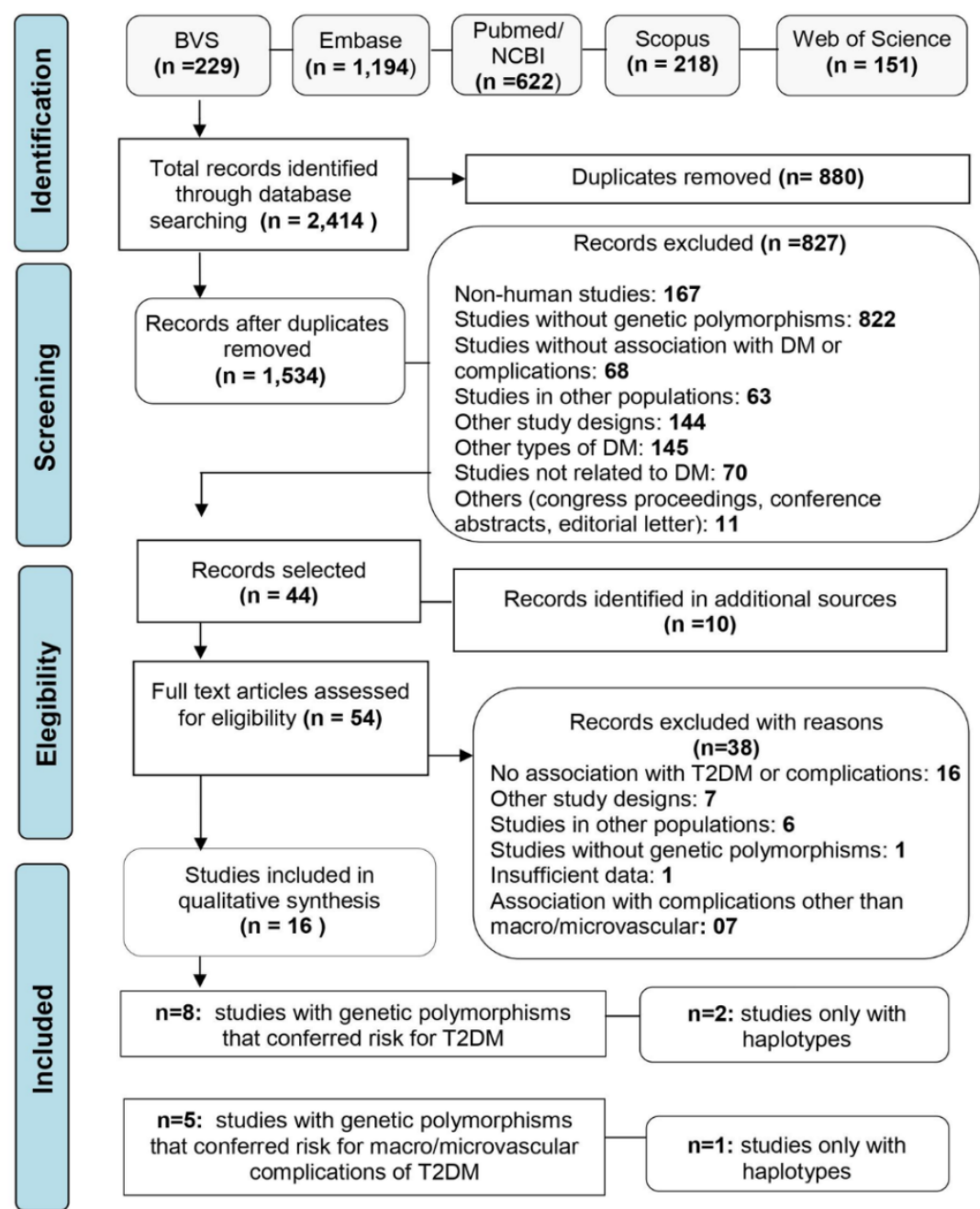

Figure 1. PRISMA flow-chart of the study selection process. Abbreviations: $B V S=$ Virtual health library; $D M=$ Diabetes Mellitus; $\mathrm{N}=$ absolute frequency; $\mathrm{NCBI}=$ National Center for Biotechnology Information; T2DM = Type 2 Diabetes Mellitus

\section{Study characteristics}

The 10 studies of T2DM susceptibility were published between 2005 and 2019 and performed in five federative units: four in the Rio Grande do Sul, three in São Paulo, and one each in Minas Gerais, Goiás, and Distrito Federal. The mean age of the patients with T2DM ranged between 47 and 60.48 years, while for controls it ranged between 44 and 66.11 years. The predominant ethnicity was Caucasian and European descent. Four studies did not describe the ethnicity of the population. The main characteristics of these studies are presented in Table 1. 
Table 1. Sociodemographic characteristics of studies that showed risk for the development of T2DM in the Brazilian population.

\begin{tabular}{|c|c|c|c|c|c|c|c|c|}
\hline \multirow[b]{2}{*}{ Reference } & \multirow[b]{2}{*}{ State } & \multirow[b]{2}{*}{ Ethnicity } & \multicolumn{3}{|c|}{ Case Group } & \multicolumn{3}{|c|}{ Control Group } \\
\hline & & & F (n) & M (n) & Mean age & $\mathbf{F}$ & M & Mean age \\
\hline Assmann et al., 2014 & RS & Caucasian & 467 & 486 & 59.3 & 262 & 273 & 44 \\
\hline Barra et al., 2012 & DF & NR & 87 & 26 & 58.6 & 117 & 22 & 56.5 \\
\hline Dora et al., 2010 & RS & European descent & 558 & 499 & 47.4 & 191 & 325 & 46.2 \\
\hline Bagarolli et al., 2010 & SP & $\mathrm{NR}$ & 109 & 102 & 59 & 80 & 120 & 54 \\
\hline Errera et al., 2006 & SP & $\begin{array}{l}\text { European descent, } \\
\text { Brazilian and } \\
\text { African-Brazilian }\end{array}$ & NR & NR & 55.43 & NR & NR & 66.11 \\
\hline Rodrigues et al., 2019 & MG & NR & 83 & 19 & 56 & 50 & 12 & 53 \\
\hline Pinheiro et al., 2013 & GO & Black and White & 83 & 37 & 60.48 & 96 & 51 & 58.98 \\
\hline Crispim et al., 2005 & RS & Caucasian & 243 & 146 & 57.8 & NR & NR & NR \\
\hline $\begin{array}{l}\text { Vendramini et al., } \\
2010\end{array}$ & SP & Japanese-Brazilians & 100 & 100 & 55 & 128 & 72 & 52 \\
\hline Leiria et al., 2014 & RS & NR & 571 & 406 & 59.2 & 191 & 325 & 46.2 \\
\hline
\end{tabular}

The six studies of complications' susceptibility in the T2DM were published between 2005 and 2015 and performed in two different regions: five in the Rio Grande do Sul, one in Minas Gerais. The mean age for the case group ranged between 45.17 and 62.1 years, whereas for the control group it ranged between 48.51 and 61.4 years. Similarly, the predominant ethnicity was also Caucasian/European descent. The main characteristics of these studies were presented in Table 2.

Table 2. Sociodemographic characteristics of studies that showed risk for the development of T2DM complications in Brazilian patients.

\begin{tabular}{|c|c|c|c|c|c|c|c|c|}
\hline \multirow[b]{2}{*}{ Reference } & \multirow[b]{2}{*}{ State } & \multirow[b]{2}{*}{ Ethnicity } & \multicolumn{3}{|c|}{ Case Group } & \multicolumn{3}{|c|}{ Control Group } \\
\hline & & & $\mathbf{F}$ & M & Mean age & $\mathbf{F}$ & M & Mean age \\
\hline Canani et al., 2005 & RS & Black and White & 236 & 277 & 59.7 & 339 & 190 & 58.3 \\
\hline Crispim et al., 2010 & RS & Caucasian & 98 & 144 & 60.6 & 164 & 95 & 61.1 \\
\hline Errera et al.,2007 & RS & European descent & 100 & 67 & 45.17 & 133 & 201 & 48.51 \\
\hline Rodrigues et al., 2015 & MG & NR & 51 & 15 & 57 & 32 & 4 & 52,5 \\
\hline Sesti et al., 2015 & RS & Caucasian & 66 & 102 & 62.1 & 188 & 143 & 59.9 \\
\hline Souza et al., 2015 & RS & Black and White & 125 & 162 & 60.2 & 185 & 96 & 61.4 \\
\hline
\end{tabular}

Abbreviations: $\mathrm{F}$ = female; $\mathrm{M}=$ male; $\mathrm{NR}$ = not reported; $\mathrm{RS}=$ Rio Grande do Sul; $\mathrm{MG}=$ Minas Gerais.

\section{Risk of methodological bias in studies}

All studies included in this review evidenced a low risk of methodological bias (Figure 2). None of the studies received "No" as an answer. All studies reported "Yes" for questions 1-5, 8, and 10. Question 9 was considered not applicable for our study.

For questions 6 and 7, most studies were reported as unclear, achieving a percentage of 87\% (Question 6: Assmann et al., 2014; Bagarolli et al., 2010; Barra et al., 2012; Canani et al., 2005; Crispim et al., 2005; Crispim et al., 2010; Dora et al., 2010; Errera et al., 2006; Errera et al., 2007; Leiria et al., 2014; Rodrigues et al., 2015; Rodrigues et al., 2019; Sesti et al., 2015; Vendramini et al., 2010) and 75\% (Question 7: Assmann et al., 2014; Bagarolli et al., 2010; Barra et al., 2012; Canani et al., 2005; Dora et al., 2010; 
Errera et al., 2006; Errera et al., 2007; Leiria et al., 2014; Rodrigues et al., 2015; Rodrigues et al., 2019; Sesti et al., 2015; Vendramini et al., 2010) of the evaluated parameters, respectively.

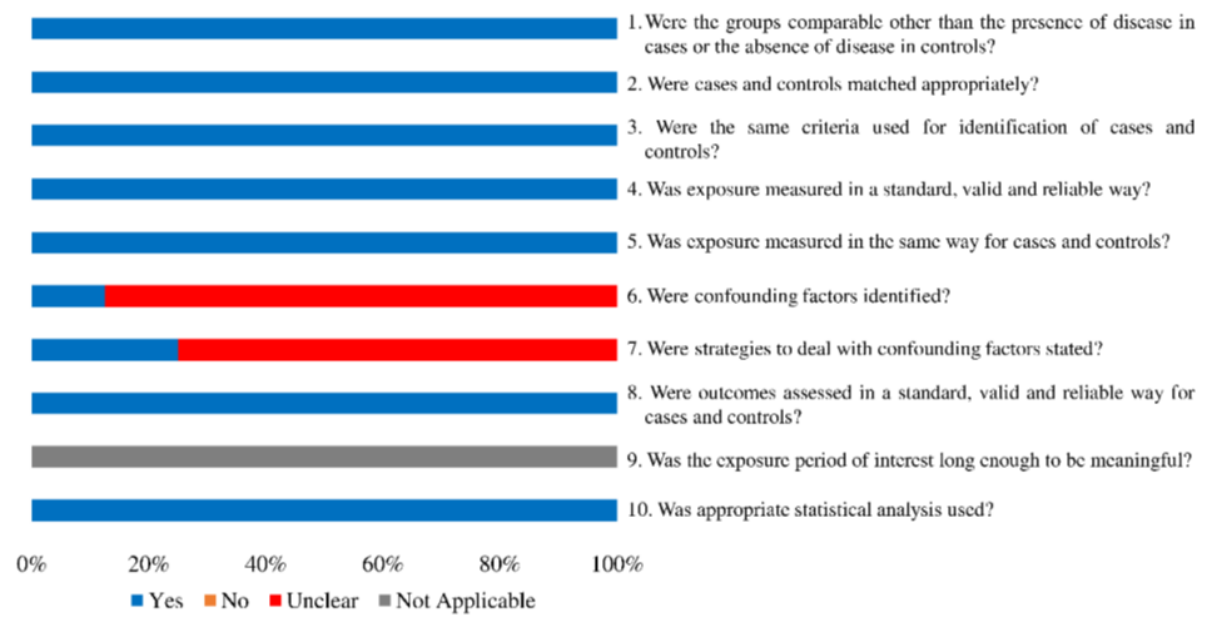

Figure 2. Graphical representation of the results from the methodological bias in the studies included in this systematic review, according to the Joanna Briggs Institute (JBI) critical appraisal tool (Institute TJB).

\section{Results of individual studies}

We identified eight polymorphisms in seven genes, which allowed us to perform a georeferencing for T2DM susceptibility and its complications. Separated by regions, the polymorphisms that conferred risk for the development of the disease in the Brazilian population were: (a) Southeast region: $\mathrm{Hp}-\mathrm{Hp} 2$ in $H P$ gene; $\varepsilon 2 / \varepsilon 3 / \varepsilon 4$ in $A P O E$ gene; insertion (I)/deletion (D) AAAT and (CCTTT)n NOS2 gene; (b) Midwest region: rs7903146 (C/T) in TCF7L2 gene; GSTT1-null genotype in GSTT1 gene; (c) South region: Thr92Ala in DIO2 gene; G1888A in MT-RNR2 (16S rRNA) gene; and rs7903146 (C/T) in TCF7L2 gene (Figure 3).

Regarding the complications of T2DM, eight polymorphisms in six genes were identified. According to regions, these polymorphisms were: (a) Southeast region: rs1800471 in $T G F-\beta 1$ gene (diabetic retinopathy) and rs1800896 in $I L-10$ gene (diabetic nephropathy); (b) South region: rs659366, rs660339 and 45 bp Ins/Del in UCP2 gene (proliferative diabetic retinopathy); $-634 \mathrm{G}>\mathrm{C}$ in $V E G F-A$ gene; $-308 \mathrm{G}>\mathrm{A}$ in $T N F$ gene (proliferative diabetic retinopathy); and $\mathrm{A} 54 \mathrm{~T}$ in $F A B P 2$ gene (diabetic nephropathy) (Figure 4).

Among all polymorphisms associated with T2DM susceptibility, the SNP rs7903146 $(\mathrm{C} / \mathrm{T})$ in the TCF7L2 gene showed the highest $\mathrm{OR}$ value $(\mathrm{C} / \mathrm{C}$ vs $\mathrm{T} / \mathrm{T}$ : $\mathrm{OR}=$ 4.04; $95 \% \mathrm{CI}=1.48-11.0 ; \mathrm{P}=0.004)$ described in two different studies. Table S1 details the information for each study of T2DM risk. On the other hand, the most common complication among patients with diabetes was diabetic retinopathy, with the highest OR values for SNP rs1800471 $(25 \mathrm{C} / \mathrm{G})$, in the $T G F-\beta 1$ gene $(\mathrm{G} / \mathrm{C}: \mathrm{OR}=5.865 ; 95 \% \mathrm{CI}=$ 1.685-20.413; $\mathrm{P}=0.004)(\underline{\text { Table } \mathrm{S} 2})$. 


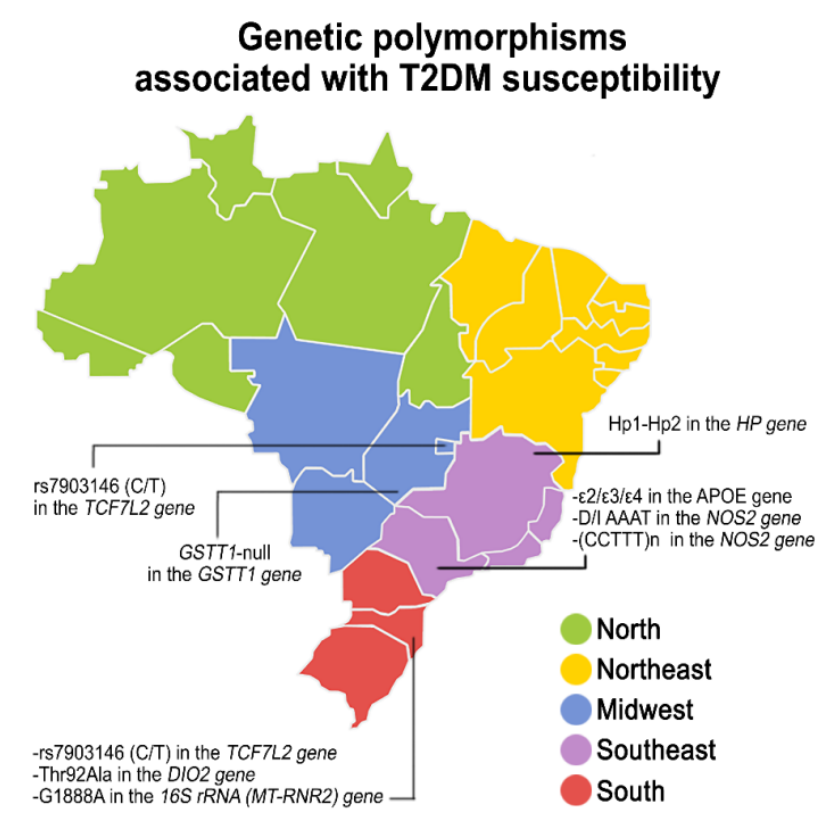

Figure 3. Georeferencing of the polymorphisms associated with the type 2 diabetes mellitus susceptibility in the Brazilian population: Abbreviations: T2DM: type 2 diabetes mellitus; Genes: APOE: apolipoprotein E; DIO2: type 2 deiodinase; GSTT1: glutathione S-transferase theta 1; HP: haptoglobin; NOS2: nitric oxide synthase 2; TCF7L2: transcription factor 7-like 2; $16 \mathrm{~S} r R N A$ (MT-RNR2): mitochondrially encoded 16S RNA.

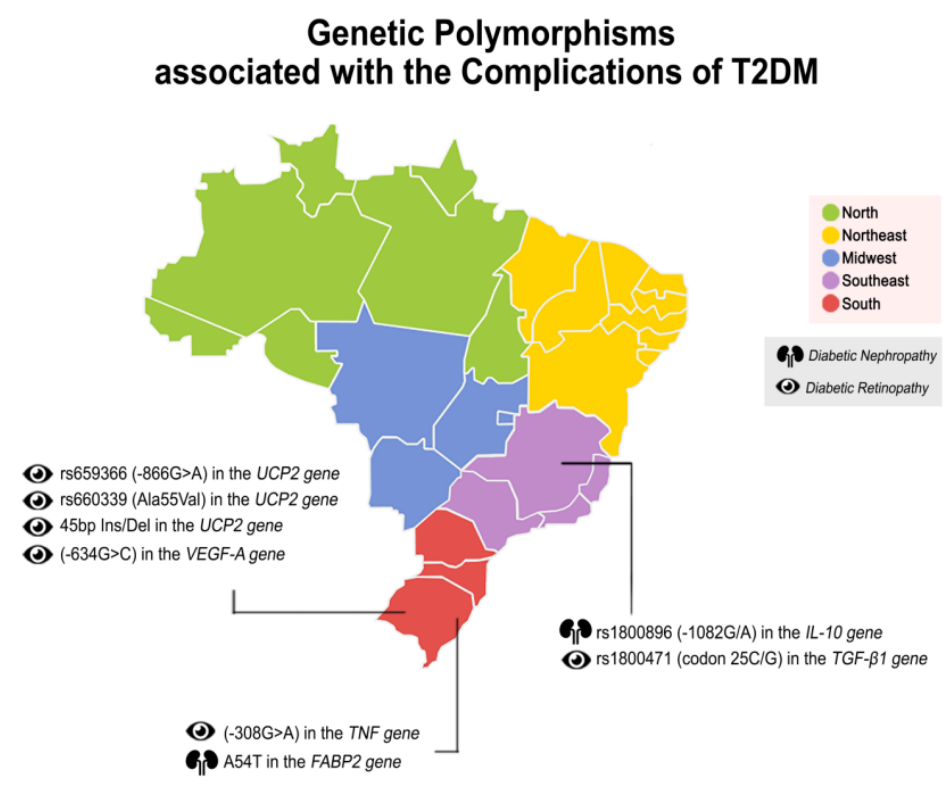

Figure 4. Georeferencing of the polymorphisms associated with the susceptibility of macro/microvascular complications of type 2 diabetes mellitus in the Brazilian population: Abbreviations: T2DM: type 2 diabetes mellitus; Genes: FABP2: fatty acid binding protein 2 ; IL-10: interleukin $10 ; T G F-\beta 1$ : transforming growth factor beta $1 ; T N F$ : tumor necrosis factor; $U C P 2$ : uncoupling protein-2; $V E G F-A$ : vascular endothelial growth factor $\mathrm{A}$. 
In haplotype analysis, two sets were associated with T2DM susceptibility: T45G, G276T, and A349G (G/G/A) in the ADIPOQ gene; and rs225017 (T/A) e Thr92Ala (Ala/Ala/T/T), in the DIO2 gene. For complications, two sets in the UCP2 gene showed significant associations in independent studies: rs659366 (-866G $>\mathrm{A})$, rs660339 (Ala55Val), and 45bp Ins/Del (A/Val/Ins+A/Val/Ins), for proliferative diabetic retinopathy and diabetic nephropathy (Table S3).

\section{DISCUSSION}

To our knowledge, this is the first systematic review to explore the genetic polymorphisms associated with the risk of T2DM development and its complications among Brazilian patients in case-control studies. Overall, eight polymorphisms were riskassociated for T2DM and eight to complications in the population with diabetes. The genes related to the disease in our study were involved in four major mechanisms: glycolytic dysregulation and lipid metabolism, insulin resistance, and inflammatory processes.

The single nucleotide polymorphism (SNP) rs7903146 (C/T) in the gene of transcription factor 7-like 2 (TCF7L2) was reported in two different studies. Assmann et al. (2014) and Barra et al. (2012) found risks that ranged from 1.31 to 4.04. Both studies found greater risks for the mutant genotype (TT) when compared to the heterozygote (CT), suggesting that $\mathrm{C}$ mutant allele has an additive effect on disease susceptibility. Moreover, although the study by Assmann et al. (2014) found lower OR values, the authors used a larger sample and a more robust genotyping method.

TCF7L2 gene encodes a transcription factor, which plays an important role in pancreatic islet development and adipogenesis through the Wnt signaling pathway. This transcription factor forms heterodimers with beta-catenin, a cytoplasmic protein, and induces the expression of several important genes for glycolytic metabolisms, such as Glucagon-like peptide-1 (GLP-1), insulin gene (INS), and genes encoding proteins involved in insulin granule processing and exocytosis (Assmann et al., 2014).

Genetic variations in the TCF7L2 gene can interfere in its function and metabolic processes, increasing the susceptibility for T2DM (Assmann et al., 2014). Furthermore, this gene has been extensively studied in different populations (Cauchi et al., 2006; Humphries et al., 2006; Marquezine et al., 2008), and several meta-analyses have shown the impact of genetic variants on the TCF7L2 gene (Tong et al., 2009; Zhang et al., 2013; Liu et al., 2015).

Some genetic alterations were directly related to insulin resistance. The polymorphism Thr92Ala in the DIO2 gene is suggested to decrease the enzymatic activity of type 2 deiodinase, reducing the conversion of thyroxine (T4) in the active hormone (T3), down-modulating the expression of glucose transporter 4 (GLUT-4) (Dora et al., 2010; Leiria et al., 2014). Individuals with Ala/Ala homozygous genotype exhibited hyperinsulinemia, worse glycemic control (increased hemoglobin A1C (HbAlc)), and a $20 \%$ reduction in glucose consumption (Dora et al., 2010; Leiria et al., 2014). However, several studies with Thr92Ala polymorphism in other populations have failed to associate it with the disease (Mentuccia et al., 2005; Grarup et al., 2007; Maia et al., 2007), which may be related to the highly mixed Brazilian ethnicity.

Nevertheless, Leiria et. al. (2014) correlated the Ala/Ala - T/T haplotypes for the rs225017 (T/A) and Thr92Ala polymorphisms in the DIO2 gene with increased 
susceptibility to T2DM in Brazilian individuals. Patients with the Ala/Ala - T/T haplotype had higher fasting insulin values and presented higher homeostatic model assessment for insulin resistance (HOMA-IR) levels than patients with other genotype combinations ( $\mathrm{P}=$ 0.001 and $\mathrm{P}=0.010$, respectively). These data were similar to findings by Mentuccia et al. (2005) and Dora et al. (2010) and may facilitate predisposition to T2DM.

The insertion (I)/deletion (D) AAAT and (CCTTT)n polymorphisms of the NOS2 promoter gene are related to hyperglycemia and insulin resistance (Bagarolli et al., 2010) due to the increase in gene transcription. The enhancement of nitric oxide produced is deleterious to insulin-sensitive tissues, promoting insulin resistance and increasing T2DM susceptibility (Bagarolli et al., 2010). The genetic study by Bagarolli et al. (2010) with the Brazilian population showed that patients with long repeats of (CCTTT)n ( $>11$ repeats) are more susceptible to T2DM (OR=1.51; IC 95\% $=1-2.28 ; \mathrm{P}=0.047)$. Similarly, the I allele for AAAT polymorphism increased 1.7-fold the risk for the disease $(95 \% \mathrm{CI}=1.02-2.86$; $\mathrm{P}$ $=0.039$ ) (Bagarolli et al., 2010). Morris et al. (2002) found a similar result in their study with Caucasian Anglo-Celtic/European individuals.

The allele 1888A of G1888A polymorphism in the 16S rRNA (MT-RNR2) gene also was associated with the disease due to insulin resistance mechanisms. Crispim et al. (2005) found 3.8-fold risk increased for T2DM in the Brazilian population, a conflicting data with Perucca-Lostanlen et al. (2000) study in the French population. Although the action of this polymorphism is not completely elucidated, it is suggested that insulin resistance is the main alteration (Perucca-Lostanlen et al., 2000; Crispim et al., 2005).

As a chronic disease, pancreatic cell damage caused by oxidative stress is a postulated mechanism in the etiology of T2DM (Pinheiro et al., 2013). Pancreatic beta cells are more sensitive to changes in the antioxidant system, such as Glutathione S-Transferases (GST) system, associated with the disease' susceptibility (Pinheiro et al., 2013. GSTT1-null genotype increased 3.2-fold the risk for T2DM and was related to higher levels of triglycerides and very-low-density lipoprotein (VLDL) cholesterol (Pinheiro et al., 2013).

Despite the study by Pinheiro et al. (2013) showed no association between the GSTM1-null genotype and T2DM susceptibility, this variant was shown to be related to hyperglycemia, high HbAlc levels, and blood pressure. However, the data shown in the literature regarding the associations of these polymorphisms with T2DM in other populations are conflicting (Amer et al., 2011; Ramprasath et al., 2011; Mastana et al., 2013), but demonstrate a correlation between GSTMI-null genotype with dyslipidemia, changes in blood glucose levels, and high blood pressure (Wang et al., 2006; Amer et al., 2011; Ramprasath et al., 2011).

Oxidative damage was also a mechanism associated with the disease in Rodrigues et al. (2019) study with the $H P$ gene. Haptoglobin (Hp) is a glycoprotein that prevents Hemoglobin-related oxidative damage, and genotypes/phenotypes can be present as Hp1 or $\mathrm{Hp} 2$, which differs in molecular structure: $\mathrm{Hp} 1$ is a single linear homodimer while $\mathrm{Hp} 2$ is a cyclic polymer (Rodrigues et al., 2019). These structural differences also implicate functional modifications, such as clearance rates of the Haptoglobin-Hemoglobin complex (Rodrigues et al., 2019). Individuals with $\mathrm{Hp} 1-\mathrm{Hp} 1$ genotypes showed a 3.038-fold increased risk for T2DM in the additive model (95\% IC $=1.127-8.192 ; \mathrm{P}=0.036)$.

However, several studies demonstrate risk for Hp2-Hp2 genotype (Quaye et al., 2006; Adinortey et al., 2011; Shi et al., 2012), which can reflect a potential genetic biomarker for the disease susceptibility in the Brazilian population. Nevertheless, Rodrigues 
et al. (2019) associated the Hp2 allele with waist circumference, body mass index, interleukin 6, and high-sensitivity $\mathrm{C}$ reactive protein levels (hs-CRP) levels.

Alterations in lipid metabolism were associated with the $A P O E$ gene, which codes apolipoprotein E, the main protein component of High-Density Lipoprotein (HDL) (Liu et al., 2019). The most studied polymorphisms in this gene are $\varepsilon 2, \varepsilon 3$ and $\varepsilon 4$ alleles that differ by the variation of single encoded amino acid. $\varepsilon 3$ allele is more frequent in the worldwide population than $\varepsilon 4$ and $\varepsilon 2$ alleles and these genetic variations can promote alterations in the lipid profile (Liu et al., 2019).

Errera et al. (2006) found an association between 83 allele and T2DM' susceptibility $(\mathrm{OR}=2.67 ; 95 \% \mathrm{CI}=1.0-6.88 ; \mathrm{P}=0.04)$, data in agreement with other studies on genetic association with disease and its complications (Araki et al., 2003; Liu et al., 2003). The main mechanism involved with T2DM susceptibility is the increase in triglycerides levels (Saxena et al., 2007). Hyperlipidemia can act as a predisposing factor to insulin resistance and, consequently, to the disease, since changes in lipid metabolism can be one of the triggering pathways for T2DM (Araki et al., 2003; Liu et al., 2003; Errera et al., 2006).

Lipid metabolism alterations were also related in the Vendramini et al. (2010) study (Table S3). The haplotype GGA for the SNPs T45G, G276T, and A349G in the ADIPOQ gene showed susceptibility for $\mathrm{T} 2 \mathrm{DM}$ in the Brazilian population $(\mathrm{P}=0.0003)$. In a separate analysis, polymorphisms were not shown to be associated with disease susceptibility. However, the GGA haplotype correlated with decreased levels of adiponectin hormone encoded by the $A D I P O Q$ gene, involved in the breakdown of fatty acids and regulation of glucose levels (Vendramini et al., 2010).

The T45G and G276T genetic variants are the most studied and associated with T2DM and the study by Vendramini et al. (2010) is the first to correlate this haplotype with the disease and the exact mechanisms that these SNPs can affect the release of adiponectin still not clear. However, the hormonal decrease can result in insulin resistance and dyslipidemia, mechanisms involved with T2DM etiology (Vendramini et al., 2010).

Regarding the complications of T2DM in the Brazilian population, the most common one was proliferative diabetic retinopathy. The main mechanisms involved were oxidative damage and inflammatory processes. The polymorphisms rs659366 (-866G $>A)$, $45 \mathrm{bp} \mathrm{Ins/Del,} \mathrm{and} \mathrm{rs660339} \mathrm{(Ala55Val)} \mathrm{in} \mathrm{uncoupling} \mathrm{protein-2} \mathrm{(UCP2)} \mathrm{gene} \mathrm{were} \mathrm{strongly}$ associated with diabetic retinopathy in the study by Crispim et al. (2010) being the first study, to our knowledge, to associate these polymorphisms and the complication (Crispim et al., 2010).

Furthermore, the authors also associated the $\mathrm{A} / \mathrm{Val} / \mathrm{Ins}+\mathrm{A} / \mathrm{Val} / \mathrm{Ins}$ haplotype with a 5.30-fold increase in the risk of developing complications (95\% CI: 2.23-12.38; $\mathrm{P}=0.00001$ ) (Crispim et al., 2010) (Table S3). The same haplotype was related in Souza et al. (2015) $(\mathrm{OR}=2.136 ; 95 \% \mathrm{CI}=1.036-4.404 ; \mathrm{P}=0.040)$ in susceptibility for diabetic nephropathy, due to decreased glomerular filtration rate (Table S3).

UCP2 belongs to the family of mitochondrial anion carrier proteins and uncouples substrate oxidation from ATP synthesis, dissipating potential energy from the membrane and, consequently, decreasing ATP production by the respiratory chain. This decoupling reduces the formation of reactive oxygen species (ROS). These polymorphisms are suggested to reduce the expression of $U C P 2$, decreasing the protection against oxidative damage to tissues and promoting cell damage to the retina (Crispim et al., 2010). 
Polymorphisms of cytokine genes were described in $T N F, V E G F-A$, and $T G F-\beta 1$. $T N F$ gene encodes the tumor necrosis factor-alpha (TNF- $\alpha$ ) and the SNP $-308 \mathrm{G}>\mathrm{A}$ was independently associated with proliferative diabetic retinopathy in Caucasian Brazilian individuals (Sesti et al., 2015) (Table S2). The A mutant is described in the literature as it increases between two to five times the expression of the TNF gene, when compared to the $\mathrm{G}$ allele. Overexpression of this gene promotes pro-apoptotic and pro-inflammatory signaling, leading to leukocyte adhesion to retinal blood vessels, blood-retinal barrier disruption, pericytes loss, capillary degeneration, and increased vascular permeability (Sesti et al., 2015).

VEGF-A is another cytokine encoded by the homonymous gene (VEGF-A), which acts in the processes of angiogenesis and vascular permeability. Diabetic retinopathy affects between 10 and $20 \%$ of the patients with diabetes and is characterized by increased vascular permeability, tissue ischemia, and neovascularization. Increased levels of this cytokine are found in the vitreous and aqueous fluids of patients with this complication (Errera et al., 2007).

Errera et al. (2007) (Table S2) found a 2.41 times greater risk in the development of diabetic retinopathy in patients carrying the $\mathrm{C}$ mutant allele for the SNP $-634 \mathrm{G}>\mathrm{C}(95 \% \mathrm{CI}$ $=1.40-4.20 ; \mathrm{P}=0.001)$. Awata et al. (2002) related a similar result in Japanese patients. This SNP is located in the $5^{\prime}$ regulatory region of the $V E G F-A$ gene and is described to increase transcription and translation activities. Overexpression of this cytokine is harmful in diabetic patients, as it induces a hyperinflammatory response. Other polymorphisms in this gene have also been associated with diabetic retinopathy (Yang et al., 2003; Ray et al., 2004).

TGF- $\beta 1$ is a cytokine encoded by the TGF- $\beta 1$ gene, which modulates ocular cell migration and proliferation. In addition, it also induces the expression of fibroblast growth factors and platelet-derived growth, which accelerate this process. The GC genotype for SNP $25 \mathrm{C} / \mathrm{G}$ in the $T G F-\beta 1$ gene is described as a risk variant for the development of diabetic retinopathy in the diabetic population worldwide. This variant can increase the risk of developing diabetic retinopathy by 5.865 times in Rodrigues et al. (2015) study (95\% $\mathrm{CI}=1.685-20.413 ; \mathrm{P}=0.004)$ (Table $\mathrm{S} 2)$, due to reduced beneficial effects on retinal cell regeneration.

The $1082 \mathrm{~A}>\mathrm{G}$ polymorphism ( $\mathrm{rs} 1800896)$ in the $I L-10$ gene (rs1800896) was associated with the risk of diabetic nephropathy in the Brazilian population (Rodrigues et al., 2015) (Table S2). The GG genotype showed a 2.357-fold greater risk for the complication (95\% CI $=1.612-9.076 ; \mathrm{P}=0.049)$ (Rodrigues et al., 2015). The rs 1800896 has been associated with the increased expression of IL-10, an anti-inflammatory cytokine, and may decrease the production of other pro-inflammatory cytokines. However, increased levels of this cytokine are associated with an exacerbated inflammatory profile (Rodrigues et al., 2015).

The imbalance between pro-inflammatory and anti-inflammatory cytokines contributes to the chronic inflammation seen in T2DM (Rodrigues et al., 2015). IL-10 also plays an important role in regulating and maintaining kidney function. In the kidney, IL-10 induces mesangial cell proliferation through increased production of growth factors, cytokines, and chemokines (Rodrigues et al., 2015). The proliferation promotes tubulointerstitial changes, such as cell hypertrophy, thickening of the glomerular base, mesangial matrix accumulation, and proteinuria (Polina et al., 2017). According to Polina et 
al. (2017), the role of IL-10 in diabetic nephropathy can be considered a paradox. The main function of IL-10 is to control inflammation, but its low expression would also be harmful, as it represents a loss of anti-inflammatory protection.

Another gene related to diabetic nephropathy in the Brazilian population was $F A B P 2$, which encodes Fatty Acid Binding Protein 2, responsible for acting on the absorption of long-chain fatty acids (Canani et al., 2005). Canani et al. (2005) (Table S2) were the first to relate the A54T polymorphism with the complication in the Brazilian population, where patients with diabetes were two to three times more likely to develop the complication. It is suggested that this SNP decreases the absorption capacity of long-chain fatty acids (Canani et al., 2005). This variant is correlated to higher levels of saturated fatty acids, especially stearic and palmitic acids, as well as the development of microalbuminuria and proteinuria in the early stages of T2DM (Perassolo et al., 2003). These data indicate that A54T SNP in the FABP2 gene may be an important genetic marker for the disease, especially in the Brazilian population.

We found several limitations in our study. First, there are few studies on the genetic epidemiology of T2DM and its complications in the Brazilian population, which limited our findings. Second, we included only case-control studies, applicable to determine the degree of associations between various risk factors and outcomes providing better quality information on exposures. Third, there is a potential selection bias for studies of polymorphisms associated with the T2DM complications, since the search strategy was formulated for studies that addressed risk-variants for disease susceptibility. Data related to complications are characterized as an additional result. Furthermore, only macro and microvascular complications were considered. Moreover, due to the heterogeneity of the data, it was not possible to summarize the data using the meta-analysis.

Thus, some measures were applied to reduce the most common errors of systematic reviews. The study methodology followed current systematic review guidelines which include a peer-reviewed search strategy without language or date restrictions, selection of independent studies, data extraction and assessment of study quality.

In conclusion, our results suggest that the main mechanisms involved in T2DM susceptibility and its complications were dysregulation of glycolytic and lipid metabolism, insulin resistance, and inflammatory processes. Although some polymorphisms in the development of T2DM are common to other regions, such as for the TCF7L2 gene, the Brazilian population has important genetic variants that provide greater susceptibility to the disease, like for $\mathrm{HP}$ and $\mathrm{DIO} 2$ genes. In addition, the Brazilian population is characterized as a highly mixed population and the genetic background may be different within our country. The rs7903146 (C/T) polymorphism in the TCF7L2 gene was associated with the disease in two different Brazilian regions: Midwest and South, showing itself as a potential genetic marker. Similarly, variants in the UCP2 gene were associated with the development of diabetic nephropathy and retinopathy.

Considering the magnitude of the disease in Brazil, further research is needed to characterize the genetic basis of the disease in our population. Furthermore, this is the first study to map risk variants in the Brazilian population for T2DM and its complications, listing the main mechanisms related to the disease' pathophysiology. With this mapping, we aim to contribute to the development of molecular diagnostic technologies for the disease, such as the development of a genetic panel for T2DM susceptibility in the Brazilian population. In addition, our genetic screening also provides a basis for the development of 
precision therapeutic strategies and preventive medicine, assisting in health strategies aimed at the prevention or early detection of the disease/complications.

\section{ACKNOWLEDGMENTS}

The authors would like to thank Filipe Reis Dias de Jesus (FRDJ), professor of Librarianship at the Federal University of Goiás (UFG), and Márcia dos Santos, librarian at the University of São Paulo (USP), for performing the peer review of the electronic search strategy (PRESS).

This research was supported by personal resources from the coordinators (Rodrigo da Silva Santos, Ph.D. and Angela Adamski da Silva Reis, Ph.D.).

\section{CONFLICTS OF INTEREST}

The authors declare no conflict of interest.

\section{REFERENCES}

Adinortey MB, Gyan BA, Adjimani JP, Nyarko PE, et al. (2011). Haptoglobin polymorphism and association with complications in Ghanaian type 2 diabetic patients. Indian J. Clin. Biochem. 26: 366-372. DOI: 10.1007/s12291011-0141-3.

Amer MA, Ghattas MH, Abo-Elmatty DM and Abou-El-Ela SH (2011). Influence of glutathione S-transferase polymorphisms on type-2 diabetes mellitus risk. Genet. Mol. Res. 10: 3722-3730. DOI: 10.4238/2011.October.31.14.

Araki S-I, Koya D, Makiishi T, Sugimoto T, et al. (2003). APOE polymorphism and the progression of diabetic nephropathy in Japanese subjects with type 2 diabetes: results of a prospective observational follow-up study. Diabetes Care. 26: 2416-2420. DOI: 10.2337/diacare.26.8.2416.

Assmann TS, Duarte GCK, Rheinheimer J, Cruz LA, et al. (2014). The TCF7L2 rs7903146 (C/T) polymorphism is associated with risk to type 2 diabetes mellitus in Southern-Brazil. Arq. Bras. Endocrinol. Metabol. 58: 918-925. DOI: $10.1590 / 0004-2730000003510$.

Awata T, Inoue K, Kurihara S, Ohkubo T, et al. (2002). A common polymorphism in the 5'-untranslated region of the VEGF gene is associated with diabetic retinopathy in type 2 diabetes. Diabetes. 51: 1635-1639. DOI: 10.2337/diabetes.51.5.1635.

Bagarolli RA, Saad MJA and Saad STO (2010). Toll-like receptor 4 and inducible nitric oxide synthase gene polymorphisms are associated with Type 2 diabetes. J. Diabetes Complications. 24: 192-198. DOI: 10.1016/j.jdiacomp.2009.03.003.

Barra GB, Dutra LAS, Watanabe SC, Costa PGG, et al. (2012). Association of the rs7903146 single nucleotide polymorphism at the Transcription Factor 7-like 2 (TCF7L2) locus with type 2 diabetes in Brazilian subjects. Arq. Bras. Endocrinol. Metabol. 56: 479-484. DOI: 10.1590/s0004-27302012000800003.

Canani LH, Costa LA, Crispim D, Gonçalves dos Santos K, et al. (2005). The presence of allele D of angiotensinconverting enzyme polymorphism is associated with diabetic nephropathy in patients with less than 10 years duration of Type 2 diabetes. Diabet Med. 22: 1167-1172. DOI: 10.1111/j.1464-5491.2005.01622.x.

Cauchi S, Meyre D, Dina C, Choquet H, et al. (2006). Transcription factor TCF7L2 genetic study in the French population: expression in human $\beta$-cells and adipose tissue and strong association with type 2 diabetes. Diabetes. 55: 2903-2908. DOI: 10.2337/db06-0474.

Correr CJ, Coura-Vital W, Frade JCQP, Nascimento RCRM, et al. (2020). Prevalence of people at risk of developing type 2 diabetes mellitus and the involvement of community pharmacies in a national screening campaign: a pioneer action in Brazil. Diabetol. Metab. Syndr. 12: 89. DOI: 10.1186/s13098-020-00593-5.

Crispim D, Canani LH, Gross JL, Carlessi RM, et al. (2005). The G1888A variant in the mitochondrial 16S rRNA gene may be associated with Type 2 diabetes in Caucasian-Brazilian patients from southern Brazil. Diabet. Med. 22: 1683-1689. DOI: 10.1111/j.1464-5491.2005.01702.x.

Crispim D, Fagundes NJ, dos Santos KG, Rheinheimer J, et al. (2010). Polymorphisms of the UCP2 gene are associated with proliferative diabetic retinopathy in patients with diabetes mellitus. Clin. Endocrinol. (Oxf). 72: 612-619. DOI: $10.1111 / \mathrm{j} .1365-2265.2009 .03684 . x$. 
DeFronzo RA, Ferrannini E, Groop L, Henry RR, et al. (2015). Type 2 diabetes mellitus. Nat. Rev. Dis. Primers. 1: 15019. DOI: $10.1038 / \mathrm{nrdp} .2015 .19$.

Dora JM, Machado WE, Rheinheimer J, Crispim D, et al. (2010). Association of the type 2 deiodinase Thr92Ala polymorphism with type 2 diabetes: case-control study and meta-analysis. Eur. J. Endocrinol. 163: 427-434. DOI: 10.1530/EJE-10-0419.

Errera FI, Canani LH, Silva ME, Yeh E, et al. (2007). Functional vascular endothelial growth factor $-634 \mathrm{G}>\mathrm{C}$ SNP is associated with proliferative diabetic retinopathy: a case-control study in a Brazilian population of European ancestry. Diabetes Care. 30: 275-279. DOI: 10.2337/dc06-1399.

Errera FI, Silva ME, Yeh E, Maranduba CM, et al. (2006). Effect of polymorphisms of the MTHFR and APOE genes on susceptibility to diabetes and severity of diabetic retinopathy in Brazilian patients. Braz. J. Med. Biol. Res. 39: 883888. DOI: $10.1590 / \mathrm{s} 0100-879 \times 2006000700005$.

García-Chapa EG, Leal-Ugarte E, Peralta-Leal V, Durán-González J, et al. (2017). Genetic epidemiology of type 2 diabetes in Mexican mestizos. Biomed. Res. Int. 2017: 3937893. DOI: 10.1155/2017/3937893.

Golden SH, Yajnik C, Phatak S, Hanson RL, et al. (2019). Racial/ethnic differences in the burden of type 2 diabetes over the life course: a focus on the USA and India. Diabetologia. 62: 1751-1760. DOI: 10.1007/s00125-019-4968-0.

Grarup N, Andersen MK, Andreasen CH, Albrechtsen A, et al. (2007). Studies of the common DIO2 Thr92Ala polymorphism and metabolic phenotypes in 7342 Danish white subjects. J. Clin. Endocrinol. Metab. 92: 363-366. DOI: $10.1210 /$ jc.2006-1958.

Humphries SE, Gable D, Cooper JA, Ireland H, et al. (2006). Common variants in the TCF7L2 gene and predisposition to type 2 diabetes in UK European Whites, Indian Asians and Afro-Caribbean men and women. J. Mol. Med. (Berl). 84: 1005-1014. DOI: 10.1007/s00109-006-0108-7.

Institute TJB (2021). Critical Appraisal Tools. Available at: [https://jbi.global/critical-appraisal-tools]. Accessed Jul 16, 2021.

International Diabetes Federation (2019). IDF Diabetes Atlas Ninth edition. 2019. Available at: [https://www.diabetesatlas.org/en/resources/]. Accessed 16 Jul 2021.

Janipalli CS, Kumar MV, Vinay DG, Sandeep MN, et al. (2012). Analysis of 32 common susceptibility genetic variants and their combined effect in predicting risk of Type 2 diabetes and related traits in Indians. Diabet. Med. 29: 121127. DOI: $10.1111 / j .1464-5491.2011 .03438 . x$

Leiria LB, Dora JM, Wajner SM, Estivalet AA, et al. (2014). The rs225017 polymorphism in the 3'UTR of the human DIO2 gene is associated with increased insulin resistance. PLoS One. 9: e103960. DOI: 10.1371/journal.pone. 0103960 .

Liu L, Xiang K, Zheng T, Zhang R, et al. (2003). Co-inheritance of specific genotypes of HSPG and ApoE gene increases risk of type 2 diabetic nephropathy. Mol. Cell. Biochem. 254: 353-358. DOI: 10.1023/a:1027364121738.

Liu S, Liu J, Weng R, Gu X, et al. (2019). Apolipoprotein E gene polymorphism and the risk of cardiovascular disease and type 2 diabetes. BMC. Cardiovasc. Disord. 19: 213. DOI: 10.1186/s12872-019-1194-0.

Liu XH, Xie CG, An Y, Zhang XX, et al. (2015). Meta-analysis of the association between the rs 7903146 polymorphism at the TCF7L2 locus and type 2 diabetes mellitus susceptibility. Genet Mol Res. 14: 16856-16862. DOI: 10.4238/2015.December.14.12.

Lyssenko V and Laakso M (2013). Genetic screening for the risk of type 2 diabetes: worthless or valuable? Diabetes care. 36(Suppl 2): S120-S126. DOI: 10.2337/dcS13-2009.

Maia AL, Dupuis J, Manning A, Liu C, et al. (2007). The type 2 deiodinase (DIO2) A/G polymorphism is not associated with glycemic traits: the Framingham Heart Study. Thyroid. 17: 199-202. DOI: 10.1089/thy.2006.0298.

Malerbi DA and Franco LJ (1992). Multicenter study of the prevalence of diabetes mellitus and impaired glucose tolerance in the urban Brazilian population aged 30-69 yr. Diabetes Care. 15: 1509-1516. DOI: 10.2337/diacare.15.11.1509.

Marquezine GF, Pereira AC, Sousa AG, Mill JG, et al. (2008). TCF7L2 variant genotypes and type 2 diabetes risk in Brazil: significant association, but not a significant tool for risk stratification in the general population. BMC. Med. Genet. 9: 106. DOI: 10.1186/1471-2350-9-106.

Mastana SS, Kaur A, Hale R and Lindley MR (2013). Influence of glutathione S-transferase polymorphisms (GSTT1, GSTM1, GSTP1) on type-2 diabetes mellitus (T2D) risk in an endogamous population from north India. Mol. Biol. Rep. 40: 7103-7110. DOI: 10.1007/s11033-013-2833-7.

McGowan J, Sampson M, Salzwedel DM, Cogo E, et al. (2016). PRESS Peer Review of Electronic Search Strategies: 2015 Guideline Statement. J. Clin. Epidemiol. 75: 40-46. DOI: 10.1016/j.jclinepi.2016.01.021.

Mentuccia D, Thomas MJ, Coppotelli G, Reinhart LJ, et al. (2005). The Thr92Ala deiodinase type 2 (DIO2) variant is not associated with type 2 diabetes or indices of insulin resistance in the old order of Amish. Thyroid. 15: 12231227. DOI: $10.1089 /$ thy.2005.15.1223.

Moher D, Liberati A, Tetzlaff J, Altman DG, et al. (2009). Preferred reporting items for systematic reviews and metaanalyses: the PRISMA statement. PLoS Med. 6: e1000097. DOI: 10.1371/journal.pmed.1000097.

Moola S, Munn Z, Tufanaru C, Aromataris E, et al. (2020). JBI Manual for Evidence Synthesis. In: Chapter 7: Systematic reviews of etiology and risk (Aromataris E, Munn Z). JBI, 2020. Available at: 
[https://wiki.jbi.global/display/MANUAL/Chapter+7\%3A+Systematic+reviews +of+etiology+and+risk]. Accessed $16 \mathrm{Jul} 2021$.

Morris BJ, Markus AM, Glenn CL, Adams DJ, et al. (2002). Association of a functional inducible nitric oxide synthase promoter variant with complications in type 2 diabetes. J. Mol. Med. 80: 96-104. DOI: 10.1007/s00109-001-02871.

Nilson EAF, Andrade RDCS, de Brito DA and de Oliveira ML (2020). Custos atribuíveis a obesidade, hipertensão e diabetes no Sistema Único de Saúde, Brasil, 2018. Rev Panam Salud Publica. 44: e32. DOI: 10.26633/RPSP.2020.32.

Ouzzani M, Hammady H, Fedorowicz Z and Elmagarmid A (2016). Rayyan - a web and mobile app for systematic reviews. Syst. Rev. 5: 210. DOI: 10.1186/s13643-016-0384-4.

Perassolo MS, Almeida JC, Prá RL, Mello VD, et al. (2003). Fatty acid composition of serum lipid fractions in type 2 diabetic patients with microalbuminuria. Diabetes Care. 26: 613-618. DOI: 10.2337/diacare.26.3.613.

Perucca-Lostanlen D, Narbonne H, Hernandez JB, Staccini P, et al. (2000). Mitochondrial DNA variations in patients with maternally inherited diabetes and deafness syndrome. Biochem. Biophys. Res. Commun. 277: 771-775. DOI: 10.1006/bbrc.2000.3751.

Pinheiro DS, Rocha Filho CR, Mundim CA, Júnior P de M, et al. (2013). Evaluation of glutathione S-transferase GSTM1 and GSTT1 deletion polymorphisms on type-2 diabetes mellitus risk. PLoS One. 8: e76262. DOI: 10.1371/journal.pone.0076262.

Polina ER, da Silva Pereira BL, Crispim D, Sbruzzi RC, et al. (2017). Association of $-1082 \mathrm{~A}>\mathrm{G}$ polymorphism in the Interleukin-10 gene with estimated glomerular filtration rate in type 2 diabetes. Kidney. Blood. Press. Res. 42: 1164-1174. DOI: $10.1159 / 000485863$.

Quaye IK, Ababio G and Amoah AG (2006). Haptoglobin 2-2 phenotype is a risk factor for type 2 diabetes in Ghana. $J$. Atheroscler. Thromb. 13: 90-94. DOI: 10.5551/jat.13.90.

Ramprasath T, Senthil Murugan P, Prabakaran AD, Gomathi P, et al. (2011). Potential risk modifications of GSTT1, GSTM1 and GSTP1 (glutathione-S-transferases) variants and their association to CAD in patients with type-2 diabetes. Biochem. Biophys. Res. Commun. 407: 49-53. DOI: 10.1016/j.bbrc.2011.02.097.

Ray D, Mishra M, Ralph S, Read I, et al. (2004). Association of the VEGF gene with proliferative diabetic retinopathy but not proteinuria in diabetes. Diabetes. 53: 861-864. DOI: 10.2337/diabetes.53.3.861.

Rodrigues KF, Pietrani NT, Carvalho LML, Bosco AA, et al. (2019). Haptoglobin levels are influenced by Hp1-Hp2 polymorphism, obesity, inflammation, and hypertension in type 2 diabetes mellitus. Endocrinol. Diabetes. Nutr. 66: 99-107. DOI: 10.1016/j.endinu.2018.07.008.

Rodrigues KF, Pietrani NT, Sandrim VC, Vieira CMAF, et al. (2015). Association of a large panel of cytokine gene polymorphisms with complications and comorbidities in type 2 diabetes patients. J. Diabetes. Res. 2015: 605965. DOI: $10.1155 / 2015 / 605965$.

Rosa R, Nita ME, Rached R, Donato B, et al. (2014). Estimated hospitalizations attributable to Diabetes Mellitus within the public healthcare system in Brazil from 2008 to 2010: study DIAPS 79. Rev. Assoc. Med. Bras. 60: 222-230. DOI: 10.1590/1806-9282.60.03.010.

Saxena R, Voight BF, Lyssenko V, Burtt NP, et al. (2007). Genome-wide association analysis identifies loci for type 2 diabetes and triglyceride levels. Science. 316: 1331-1336. DOI: 10.1126/science.1142358

Sesti LF, Crispim D, Canani LH, Polina ER, et al. (2015). The -308G $>$ A polymorphism of the TNF gene is associated with proliferative diabetic retinopathy in Caucasian Brazilians with type 2 diabetes. Invest. Ophthalmol. Vis. Sci. 56: 1184-1190. DOI: 10.1167/iovs.14-15758.

Shi X, Sun L, Wang L, Jin F, et al. (2012). Haptoglobin 2-2 genotype is associated with increased risk of type 2 diabetes mellitus in northern Chinese. Genet. Test. Mol. Biomarkers. 16: 563-568. DOI: 10.1089/gtmb.2011.0246.

Souza BM, Michels M, Sortica DA, Bouças AP, et al. (2015). Polymorphisms of the UCP2 gene are associated with glomerular filtration rate in type 2 diabetic patients and with decreased UCP2 gene expression in human kidney. PLoS One. 10: e0132938. DOI: 10.1371/journal.pone.0132938.

Tong Y, Lin Y, Zhang Y, Yang J, et al. (2009). Association between TCF7L2 gene polymorphisms and susceptibility to type 2 diabetes mellitus: a large Human Genome Epidemiology (HuGE) review and meta-analysis. BMC. Med. Genet. 10: 15. DOI: 10.1186/1471-2350-10-15.

Vendramini MF, Pereira AC, Ferreira SR, Kasamatsu TS, et al. (2010). Association of genetic variants in the adiponectin encoding gene (ADIPOQ) with type 2 diabetes in Japanese Brazilians. J. Diabetes. Complications. 24: 115-120. DOI: 10.1016/j.jdiacomp.2009.01.007.

Wang G, Zhang L and Li Q (2006). Genetic polymorphisms of GSTT1, GSTM1, and NQO1 genes and diabetes mellitus risk in Chinese population. Biochem. Biophys. Res. Commun. 341: 310-313. DOI: 10.1016/j.bbrc.2005.12.195.

Wilmot E and Idris I (2014). Early onset type 2 diabetes: risk factors, clinical impact and management. Ther. Adv. Chronic. Dis. 5: 234-244. DOI: 10.1177/2040622314548679.

Yang B, Cross DF, Ollerenshaw M, Millward BA, et al. (2003). Polymorphisms of the vascular endothelial growth factor and susceptibility to diabetic microvascular complications in patients with type 1 diabetes mellitus. $J$. Diabetes. Complications. 17: 1-6. DOI: 10.1016/s1056-8727(02)00181-2. 
Zhang BC, Li WM, Zhu MY and Xu YW (2013). Association of TCF7L2 gene polymorphisms with type 2 diabetes mellitus in Han Chinese population: a meta-analysis. Gene. 512: 76-81. DOI: 10.1016/j.gene.2012.09.034. 